\title{
CONSELHO DE CLIENTES HOPE - EXEMPLO DE ADMINISTRAÇÃO PARTICIPATIVA
}

\author{
Cristiane Hazin Cordeiro de Melo Cardim ${ }^{1}$
}

\begin{abstract}
Resumo
Este artigo tem por objetivo apresentar o Conselho de Clientes, ideia inovadora implantada pelo HOPE - Hospital de Olhos de Pernambuco, e ressaltar a importância dessa iniciativa como ferramenta de participação efetiva dos clientes no processo de melhoria contínua, trazendo a visão de quem está de fora e contribuindo para elevar a qualidade do serviço prestado, evidenciando a percepção da qualidade desse serviço pelos clientes. A proposta do Conselho não é atuar como simples canal de relacionamento, mas como ferramenta de fidelização da marca. Dessa forma, a administração do hospital entende que o bom relacionamento gera boa reputação, que por sua vez gera demanda e faturamento, conferindo sustentabilidade ao negócio e cumprindo assim o seu propósito. Com o Conselho, a Ouvidoria passa a atuar como instrumento de gestão ao contar com a participação efetiva de quem consome o serviço e/ou produto. Não se pode perder de vista que o horizonte almejado é, invariavelmente, a satisfação e, nesse sentido, o Conselho de Clientes HOPE configura-se como poderosa ferramenta de transformação institucional, favorecendo mudanças e ajustes nas atividades e processos, e consequentemente o aprimoramento contínuo do serviço oferecido pelo hospital. A existência desse espaço aberto e permeável revela o nível de maturidade de uma instituição e configura grande diferencial por permitir a participação efetiva dos clientes em processos de melhoria contínua dentro da organização, influenciando de forma positiva os demais usuários do serviço ofertado pelo HOPE. A metodologia aplicada para desenvolver este trabalho foi Estudo de Caso do Conselho de Clientes HOPE e Revisão Bibliográfica.
\end{abstract}

Palavras-chave: Conselho de Clientes. Percepção. Clientes. Qualidade. Satisfação.

DOI:10.37814/2594-5068.2020v3.p245-251

1 Graduada em Fonoaudiologia pela Universidade Católica de Pernambuco e pós-graduada em Gestão de Ouvidorias pela Escola Superior de Relações Públicas. Certificada no Curso Oficial de Ouvidoria pela Associação Brasileira de Ouvidores - Seccional/PE. Membro do Conselho de Ética da ABO Seccional/PE. Ouvidora do HOPE - Hospital de Olhos de Pernambuco. (crishazin@hotmail.com) 


\begin{abstract}
This article aims to present the Client Council, an innovative idea implemented by the HOPE - Eye Hospital of Pernambuco, and highlight the importance of this initiative as a tool for effective participation of customers in the process of continuous improvement, bringing the vision of who is outside and contributing to raise the quality of the service provided by highlighting the perception of the quality of this service by customers. The Board's proposal is not to act as a simple relationship channel, but as a brand loyalty tool. Thus, the hospital administration understands that a good relationship generates a good reputation, which in turn generates demand and revenues, giving sustainability to the business and thus fulfilling its purpose. With the Council, the Ombudsman's Office acts as a management tool by counting on the effective participation of those who consume the service and/or product. It should not be overlooked that the desired horizon is invariably satisfaction, and in this sense, the HOPE Client Council is a powerful tool for institutional transformation, favoring changes and adjustments in activities and processes, and consequently continuous improvement of the service offered by the hospital. The existence of this open and permeable space reveals the level of maturity of an institution and sets great differential for allowing the effective participation of customers in continuous improvement processes within the organization, positively influencing other users of the service offered by HOPE. The methodology applied to develop this work was HOPE Client Council Case Study and Bibliographic Review.
\end{abstract}

Keywords: Client Council. Perception. Customers. Quality. Satisfaction. 


\section{INTRODUÇÃO}

O Hospital de Olhos de Pernambuco - HOPE está sempre em busca da excelência no que faz. Por isso, investe em novas tecnologias, equipamentos de ponta, profissionais altamente qualificados que buscam o conhecimento de forma constante, tudo isso com o objetivo de oferecer aos seus clientes/pacientes a melhor experiência.

Com o entendimento de que esse público deve ser o foco de seus investimentos, a instituição decidiu chegar mais perto e ouvir o que ele tem a dizer, fazendo também com que tomasse conhecimento do quanto a instituição dedica-se a oferecer sempre o melhor e ter nos clientes seus maiores aliados.

Foi esse o objetivo da diretoria e da Ouvidoria ao criar o Conselho de Clientes HOPE, instituído oficialmente em 30 de julho de 2018. O ponto de partida foi trabalhar com alguns clientes que utilizassem nossa gama de serviços, com visitas constantes ao HOPE e senso crítico para poder representar os demais clientes, contribuindo com ideias e melhorias. O propósito foi manter o foco na excelência da prestação do serviço em saúde e, ainda, no relacionamento mais estreito com os pacientes. Essa aproximação cliente/instituição não só forneceu informações às áreas administrativas competentes, como também demonstrou os esforços da instituição em oferecer qualidade.

O resultado não poderia ser diferente. Ao empoderarmos aquele grupo de clientes e tratá-los como parte dos processos, extraímos suas impressões sobre a forma como nos comunicávamos com eles. Os setores de Atendimento, Assistência, Recursos Humanos, Marketing, Supervisão Administrativa, entre outras áreas internas, foram integrados ao processo e se apropriaram das sugestões do Conselho, que proporcionaram o crescimento conjunto por meio de uma série de ações resultantes da atuação dos clientes-conselheiros, como intensificação de treinamentos envolvendo a cordialidade e acolhimento ao cliente, ações voltadas à redução do tempo de espera para atendimento e conscientização da equipe de atendimento sobre a importância das informações repassadas ao cliente.

Fica cada vez mais claro que, mesmo mantendo investimentos em fortes diferenciais tecnológicos e de estrutura, é o relacionamento com o cliente que distingue a empresa de excelência da empresa mediana. E, na área de saúde, a importância desse relacionamento é ainda mais evidente.

Este trabalho apresenta a criação do Conselho de Clientes como um divisor de águas, ao tornar o entendimento da excelência no atendimento ao cliente em diretriz institucional. É uma ideia inovadora no serviço de saúde e desperta a importância, cada vez mais imperiosa, da voz do cliente como coautor no processo de melhoria contínua, na busca pela excelência e, principalmente, como "promotor" das instituições, favorecendo o crescimento sustentável do negócio.

Hoje eu venho para o HOPE com outros olhos. Eu venho olhando, perguntando, sugerindo. Me sinto uma pessoa colaboradora. (G.L.Q. membro do Conselho de Clientes HOPE)

\section{FORMAÇÃO DO CONSELHO}

O primeiro passo para compor a formação do Conselho de Clientes HOPE foi identificar clientes 
assíduos. Por isso, eram elegíveis os clientes em tratamento quimioterápico, visto que precisam comparecer ao hospital quase mensalmente, utilizando os serviços ambulatoriais, de diagnóstico e cirúrgicos, com possibilidade de avaliar todo o atendimento.

Também era muito importante que o Conselho fosse composto por clientes com diferentes perfis econômicos e sociais. Após análise do perfil de cada um, foram selecionados formadores de opinião que iriam propagar as ideias debatidas nas reuniões com o maior número de pessoas. Um critério bastante relevante foi que o futuro conselheiro tivesse realizado registros na Ouvidoria, demonstrando postura participativa na busca por melhorias do serviço.

Definido o perfil e selecionados aqueles que seriam os potenciais conselheiros, foram enviados e-mails convite. Esse era um ponto de atenção, pois foi necessária uma amostra bem extensa para que se conseguisse captar um pequeno grupo de interessados. O ideal era um grupo de até quinze membros, para que todos pudessem interagir, pois grupos muito extensos não favorecem a participação efetiva. O Conselho de Clientes HOPE foi composto por nove membros que permaneceram atuantes até junho de 2019, em mandato de um ano. Com as atividades do primeiro Conselho encerradas, a ideia é captar novos membros para compor o $2^{\circ}$ Conselho de Clientes HOPE. O período de um ano foi definido para renovar e oxigenar o projeto.

\subsection{As Reuniões}

Escolhidos os membros, foi marcado um primeiro encontro para apresentação do projeto. Foi explicado o objetivo do Conselho e esclarecida a importância da assiduidade às reuniões. O Código de Ética do Conselho de Clientes foi entregue e assinado pelos conselheiros, com o compromisso de manterem sigilo das informações, uma vez que seriam debatidos assuntos da instituição.

Com duração máxima de três horas, as reuniões são trimestrais, pois o hospital precisa de tempo para estudar as pautas debatidas em cada assembleia, bem como analisar as recomendações discutidas e apresentar os resultados das reuniões anteriores. Mas também não se pode espaçar demais esse período, pois a opinião do consumidor tem data de validade e é preciso acompanhar o cliente para poder identificar mudanças de humor; ou seja, é necessário acompanhar por meio dos conselheiros o mínimo sinal que indique uma decisão, ação ou situação que impacte negativamente a satisfação dos clientes, levando-os a uma postura detratora.

Todas as reuniões são gravadas e filmadas, para que o registro das manifestações e discussões seja o mais fiel possível ao que transcorreu. São conduzidas pela Ouvidora do HOPE, que de modo imparcial apresenta os temas que serão trabalhados e instiga o máximo possível debates acerca do tema proposto, com o cuidado de evitar que assuntos diferentes da abordagem tratada sejam colocados à mesa. Quando isso acontece, é necessário que o representante da Ouvidoria tenha uma postura gentil, porém firme, para recusar o tema destoante e, se for o caso, informar que será tratado em outro momento. Se não for demonstrada firmeza para trazer de volta o foco para o assunto pré-definido, tópicos diversos serão abordados e a captação de informações sobre o tema central da reunião será bastante comprometida.

As atividades começam sempre com a apresentação das informações coletadas na reunião 
anterior e das proposituras de ações. São colocadas algumas questões relacionadas com o tema a ser tratado no encontro. Se o tema é atendimento, por exemplo, são feitas perguntas sobre diferenças de tratamento nas diferentes recepções, sobre a cordialidade médica, se existem fatores que mudariam sua opinião em relação a um determinado atendimento. Assim é construída a percepção de cada um em relação aos temas abordados.

Os principais pontos de colaboração do grupo foi a melhoria no atendimento; agilidade e clareza nas informações. (K. C. membro do Conselho de Clientes HOPE)

Foram convidados também gestores de algumas áreas de impacto do hospital para falar sobre cada setor, criando a oportunidade para esclarecer dúvidas e apreciar observações dos Conselheiros.

Em cada reunião, é entregue uma atividade a ser realizada externamente e tratada no próximo encontro. Se a reunião seguinte vai abordar o tema cordialidade, por exemplo, é solicitado que cada um observe se a qualidade está presente em todos os pontos de contato, ou seja, se ao marcar a consulta o operador de marcação foi cordial, se demonstrou interesse em oferecer os exames em dia e horário mais convenientes, se o operador teve paciência ao fornecer as informações necessárias. Ao chegar no HOPE, como foi recepcionado pelo concierge, se ele chamou o elevador, perguntou a qual serviço estava se dirigindo? Em resumo, é solicitado observar todos os pontos de atendimento, desde a chegada até o momento em que deixa o HOPE, observando não somente o atendimento ofertado a ele, mas também aos demais clientes. São também distribuídas perguntas a serem feitas aos familiares e amigos, com o propósito de levar ao conhecimento de um universo amplo que o HOPE tem o cliente/paciente no centro de seus cuidados. Por isso busca incessantemente, pelos olhos deles, conhecer os desafios sistêmicos a superar.

Ao fim de cada encontro, todos os dados e informações coletados são compilados e entregues à diretoria e às áreas envolvidas para tomada de ações e melhorias.

\section{SÓ O CONSELHO BASTA?}

É importante compreender que as informações coletadas representam o modo de pensar dos clientes, construídas a partir de suas experiências, vivências e observações dos serviços por eles utilizados. São na verdade conhecimentos empíricos, que devem ser analisados pela instituição de forma crítica, para posterior definição de conduta. Por isso é fundamental conhecer a percepção do maior número possível de clientes. Dessa forma, a Ouvidoria do HOPE coleta diariamente informações a respeito do serviço utilizado e transforma a percepção em indicadores de qualidade que norteiam estrategicamente a tomada de decisões.

Para sintetizar informações coletadas, surgiram no mercado diversos modelos de pesquisa e métricas. Atualmente, a métrica NPS - Net Promoter Score, criada por Fred Reichheld, nos EUA, com o objetivo de realizar a mensuração do Grau de Lealdade dos Consumidores de qualquer tipo de empresa, tem feito grande sucesso entre os especialistas da área. A métrica foi apresentada em um artigo da Harvard Business Review em 2003 (Revista da Universidade de Harvard - EUA) e vem sendo utilizada pelo HOPE desde 2017. Passamos então a analisar de forma mais profun- 
da as ressalvas dos clientes que respondiam à pesquisa. Estava claro que, embora com grande percentual de promotores e com satisfação de 93\%, em 2017 o hospital tinha percentual considerável de neutros $(21 \%)$ e detratores $(5 \%)$ que, em suas ressalvas, deixavam claro os pontos de melhorias a serem trabalhados. Dessa forma, foram desenvolvidas ações voltadas para a melhoria da infraestrutura e preço do estacionamento; de sistemas; de investimento em treinamento para melhoria da cordialidade e acolhimento; e meios para monitorar o tempo médio de permanência do cliente na instituição e assim poder agir mais efetivamente, reduzindo as insatisfações por demora no atendimento. Todas as ações acima contribuíram para o aumento da satisfação e fidelidade do cliente, comprovado por meio da evolução do NPS que, durante o período de vigência do Conselho, aumentou quatro pontos percentuais.

Os insumos produzidos pela métrica representam valioso material usado como norteador das atividades do Conselho de Clientes, o qual permite construir relacionamentos e demonstra que as oportunidades de melhoria estão relacionadas ao fortalecimento do nível de atenção, às preocupações do cliente/paciente, ao acolhimento e humanização, ressaltando que o sucesso não pode ser focado apenas nos processos e burocracias. Eficiência é importante, controlar indicadores de desempenho e traçar ciclos de melhoria de processos são passos fundamentais, mas não podem ser o foco, pois, se analisados de forma isolada, o resultado não irá considerar a satisfação do cliente. De outro modo, a empresa que pauta o atendimento na cortesia conseguirá não só a eficiência dos processos, mas garantirá a perenidade do negócio, assegurando de forma pensada, planejada e estruturada que o cliente seja surpreendido além de suas expectativas.

$\mathrm{Na}$ sociedade em que hoje vivemos, com todo arsenal tecnológico e, consequentemente, com a velocidade das informações, os clientes/pacientes estão muito mais atentos aos seus direitos e lutam por eles, valendo-se da internet como maior aliado. Buscam atitudes pautadas na ética, no respeito e na transparência das ações. Ao acompanhar a expectativa desse cliente e mensurar por meio de indicadores sua experiência em relação ao serviço prestado, e melhor, apresentar a eles, mesmo que para um pequeno grupo, os dados coletados e buscar em conjunto embasamento para tomada de decisões, fica patente o nível de amadurecimento da instituição, cujos valores se pautam na ética, transparência, respeito e valorização profissional, promovendo uma verdadeira administração participativa.

\section{CONSIDERAÇÕES FINAIS}

A ideia para a criação do Conselho de Clientes HOPE foi trazer o cliente - seu ativo mais valioso - para dentro da instituição, de forma participativa. Ouvir de verdade suas críticas e sugestões, bem como entender o que agrega valor para eles. Assim, alinhando as informações garimpadas pelo grupo e confrontando com o compilado da pesquisa mensal, fica garantido material consistente para direcionar decisões que causem impactos positivos na percepção dos clientes e, consequentemente, resultem em maior rentabilidade para o negócio.

Durante o período de atuação do primeiro grupo, observou-se que, embora muitas manifestações e sugestões pertinentes tenham sido apresentadas por eles, os conselheiros se tornaram 
os maiores promotores do HOPE. Ao tomar conhecimento dos bastidores da instituição, de todo o trabalho desenvolvido para atendê-los, passam a influenciar os demais clientes e até a modificar a postura de alguns insatisfeitos; propagam em seu ambiente social, repercutindo positivamente sobre a forma como o HOPE busca a excelência do serviço; passam a ter sentimento de pertencimento, que resulta em envolvimento, propagação positiva, preocupação com a imagem e a busca por novos clientes (indicação do hospital em ambientes de trabalho, escolas e círculos de amizades). Tudo isso corrobora a afirmação de que a experiência positiva do cliente é diferencial estratégico para a instituição.

Para o empresário alemão Karl Albrecht, autor do livro Revolução nos serviços, a administração de serviços é um enfoque organizacional global, que faz da qualidade, tal como sentida pelo cliente, a principal força motriz do funcionamento da empresa. Assim, podemos afirmar que o investimento no atendimento ao cliente visa a trazer serviços diferenciados, sendo a cordialidade e a superação de expectativas fundamentais, o que pode ser considerado estratégico nas instituições.

Diante da experiência positiva, o Conselho de Clientes do HOPE será mantido, com a expectativa de que a nova formação de conselheiros possa contribuir com percepções diferentes, tornando-os agentes atuantes e reunindo dados para embasar reestruturações e reforçar impactos positivos nos demais clientes.

\section{REFERÊNCIAS}

ALBRECHT, Karl. Revolução nos serviços: como as empresas podem revolucionar a maneira de tratar os seus clientes. São Paulo: Pioneira, 1992.

CLIENTESA. E aí, vai um conselho? Disponível em: <http://www.administradores.com.br/artigos/marketing/ seis-sigma-a-qualidade-percebida/20187/>. Acesso em: 29 maio 2019.

DIÁRIO DE PERNAMBUCO. Conselho de clientes enriquece prestação de serviço na saúde pernambucana. Disponível em:

<https://www.diariodepernambuco.com.br/noticia/vidaurbana/2019/05/conselho-de-clientes-enriquece-prestacao-de-servico-na-saude-pernambuc.html>. Acesso em: 07 maio 2019.

DIÁRIO DO COMÉRCIO. O que levar em consideração ao criar um conselho de clientes. Disponível em: <https://dcomercio.com.br/categoria/gestao/o-que-levar-em-consideracao-ao-criar-um-conselho-de-clientes-://www.scielo.br/pdf/raeel/v4n2/v4n2a02.pdf>. Acesso em: 22 maio 2019.

TOTAL GESTÃO. Satisfação dos Clientes: A garantia da continuidade do seu negócio. Disponível em: <http://www.totalgestao.com.br/site/2013/04/satisfacao-dos-clientes-a-garantia-da-continuidade-do-seu-negocio/>. Acesso em: 14 maio 2019. 